\title{
Effects of L-carnitine supplementation on respiratory distress syndrome development and prognosis in premature infants: A single blind randomized controlled trial
}

\author{
MEHMET ADNAN OZTURK ${ }^{1}$, ZEHRA KARDAS ${ }^{2}$, FATIH KARDAS $^{3}$, TAMER GUNES $^{1}$ and SELIM KURTOGLU ${ }^{1}$ \\ ${ }^{1}$ Department of Pediatrics, Division of Neonatology, Erciyes University, School of Medicine; \\ ${ }^{2}$ Department of Pediatrics, State Educational and Research Hospital of The Government; ${ }^{3}$ Department of Pediatrics, \\ Division of Pediatric Nutrition and Metabolism, Erciyes University, School of Medicine, Kayseri 38039, Turkey
}

Received January 5, 2015; Accepted November 25, 2015

DOI: $10.3892 /$ etm.2015.2964

\begin{abstract}
The aim of the present study was to investigate the efficacy of L-carnitine therapy on the occurrence and prognosis of respiratory distress syndrome (RDS). A single blind, randomized controlled trial study was conducted on 130 infants with gestational ages of 28-36 weeks. Infants were assigned to experimental groups (groups 1 and 2) and control groups (groups 3 and 4). Groups 1 and 3 consisted of infants with RDS, and groups 2 and 4 groups were composed of infants without RDS. The experimental groups were treated with carnitine. No statistically significant differences in serum carnitine levels were detected between the study and the control groups on day 1 of treatment $(\mathrm{P}=0.06)$. However, on day 7 of treatment, serum carnitine levels in the experimental groups were significantly increased $(\mathrm{P}=0.02)$, as compared with the control groups. The surfactant requirement value, which is how many rounds of surfactant therapy were required, was $1.56 \pm 0.97$ in group 1 , and $2.12 \pm 0.99$ in group $3(\mathrm{P}<0.001)$. The mean duration of mechanical ventilation required was $3.04 \pm 3.60$ days in group 1 , and $4.73 \pm 5.63$ days in group $3(\mathrm{P}<0.001)$. The present results indicate that carnitine supplementation in premature infants with RDS may help to increase carnitine levels, thus decreasing the duration of mechanical ventilation and surfactant requirement.
\end{abstract}

\section{Introduction}

Respiratory distress syndrome (RDS) is among the most common diseases of preterm infants. RDS is caused by a

Correspondence to: Dr Fatih Kardas, Department of Pediatrics, Division of Pediatric Nutrition and Metabolism, Erciyes University, School of Medicine, Talas Street, Kayseri 38039, Turkey

E-mail: fkardas@erciyes.edu.tr

Key words: carnitine supplementation, respiratory distress syndrome, preterm, surfactant deficiency decreased production or secretion of pulmonary surfactant (1). Deficient synthesis and release of surfactant is associated with asphyxia, hypoxaemia, pulmonary ischaemia, hypovolemia, hypotension and cold stress (1). Numerous causes of RDS have been identified, and the factors suspected to be involved in the pathogenesis of RDS are numerous (2). In recent years, studies have identified the presence of low serum carnitine levels in preterm newborns with $\operatorname{RDS}(2,3)$.

Carnitine is a hydrophilic amino acid derivative synthesized from lysine, which serves a crucial function in $\beta$ oxidation as it transports long chain fatty acids across the mitochondrial membrane (4). Carnitine is essential for the fetus and is provided via placental transport. As the gestational age increases, fetal tissues store increasing amounts of carnitine; however, preterm infants are at an increased risk of carnitine deficiency due to low levels of $\alpha$-butyrobetaine hydroxylase, a catalyzing enzyme in the final step of the carnitine biosynthetic signaling pathway $(5,6)$. Therefore, preterm infants require exogenous carnitine supplementation for carnitine homeostasis (7). Human and cow milk-based infant formulas contain adequate amounts of carnitine for preterm infants; however, soya milk-based formulas and parenteral nutrition fluids are poor sources of carnitine (8). Therefore, preterm infants with a complicated birth or at $<32$ weeks of gestation have an increased risk of carnitine deficiency due to the challenges faced with enteral nutrition (8).

The effects of carnitine in preterm infants on nutritional or respiratory functions, specifically apnoea, have been studied in various trials $(7,8)$. Two previous studies have demonstrated that free carnitine levels were reduced in infants with RDS compared with healthy controls $(2,3)$. It has previously been demonstrated that, L-carnitine-betamethasone combination therapies significantly increase the dipalmitoyl phosphatidylcholine content of the foetal lungs and significant reduce the incidence of RDS and mortality in premature newborns, as compared with betamethasone alone $(6,9)$.

The present study aimed to observe the efficacy of L-carnitine therapy with regards to the occurrence and prognosis of RDS, the duration of mechanical ventilation required, the amount of surfactant required, and the occurrence of bronchopulmonary dysplasia (BPD). 


\section{Materials and methods}

Patients. The present study was a single blind, randomized controlled trial. Investigators and neonatologists were not provided information on the groups of patients, or informed of which patients received carnitine (Sigma-Tau, Rome, Italy). A total of 130 preterm infants (56 female and 74 male) that were observed in the neonatal intensive-care unit between January 2011 and January 2013 were included in the study. Written-informed consent was obtained from the parents of the infants. The protocol of the present study was approved by the ethics committee of the Erciyes University School of Medicine Faculty (Kayseri, Turkey). The gestational age of infants was calculated from the date of the last menstrual period of the mothers, confirmed using the New Ballard score (10).

Inclusion and exclusion criteria. The inclusion criteria for the study were as follows: Preterm infants with a gestational age of 28-36 weeks, and inclusion in the study within $6 \mathrm{~h}$ following birth. The exclusion criteria were as follows: Gestational age $<28$ weeks or $>36$ weeks, sepsis, asphyxia, congenital pneumonia or history of major congenital anomaly history, maternal gestational diabetes, maternal corticosteroid treatment (except for lung maturation) and transfusion with blood/blood products. Infants fulfilling the inclusion criteria were evaluated for RDS according to the following criteria: Respiratory rate $>60 /$ min during the $6 \mathrm{~h}$ following delivery; presence of gasping, sternal/intercostal retractions and cyanosis; hypoxemia, hypercapnia and acidosis on blood gas analysis; and compatible chest $\mathrm{x}$-ray including reticulogranular patterns, air bronchograms and diffuse alveolar atelectasis. Clinical improvement during the first $12 \mathrm{~h}$ after birth suggests transient tachypnea of the newborn (TTNB), and onset after the first $24 \mathrm{~h}$ suggests pneumonia and sepsis (11). Patients with TTNB, pneumonia, sepsis or meconium aspiration syndrome were excluded from the present study. Diagnosis of BPD was performed according to the previously described criteria: Treatment with $\mathrm{FiO}_{2}>0.21$ for $\geq 28$ days and failure of the room air challenge test at 36 weeks' postmenstrual age (12).

Recording of patient characteristics. The mode of delivery of the infant, birth time, weight, gestational age, last menstruation date of the mother, maternal history of medication usage during gestation, hypertension and premature rupture of membranes were evaluated. Apgar scores, gender, twin births and presence of intrauterine growth restriction in the infants were also recorded (13).

Patient grouping. Preterm infants were separated into infants with RDS and infants without RDS, then randomized by blocks of four in a 1:1 ratio according to their admission time to the hospital for experimental and control groups (14). The infants included in the present study were divided into an experimental and a control group. The experimental group received carnitine treatment and the control group did not. Each group was subdivided into two subgroups of patients: An RDS group and a non-RDS group. The grouping was as follows: Group 1, RDS patients that received carnitine therapy; group 2, non-RDS patients that received carnitine therapy; group 3, RDS patients that did not receive carnitine therapy; and group 4, non-RDS patients that did not receive carnitine therapy. The experimental groups consisted of groups 1 and 2, and the control groups consisted of groups 3 and 4. In the experimental group, all patients (RDS and non-RDS) received daily carnitine treatment ( $30 \mathrm{mg} / \mathrm{kg} /$ day, 3 times/day) beginning from $6 \mathrm{~h}$ to 7 days. Carnitine was administered intravenously during parenteral feeding, and then via the enteral route when the patient began enteral feeding.

Treatment. All infants that were determined to have RDS were treated with nasal continuous positive airway pressure (NCPAP). The level of NCPAP for positive end expiratory pressure ranged from $6-8 \mathrm{~cm} \mathrm{H}_{2} \mathrm{O}$. Optiflow ${ }^{\mathrm{TM}}$ neonatal nasal cannulas and an Airvo 2 humidifier were used to generate NCPAP (both Fisher \& Peykel Healthcare, Ltd., Auckland, New Zealand) (15). Infants with RDS that required an $\mathrm{FiO}_{2}$ of $>0.35-0.40$ and CPAP to sustain optimal blood $\mathrm{O}_{2}$ saturation $\left(\mathrm{PaO}_{2},>50-80 \mathrm{mmHg}\right), \mathrm{SpO}_{2}$ of $88-93 \%$ [as determined via a Nellcor $\mathrm{N}-600$ pulse oximeter (v1.1.2.0; Covidien Boulder, CO, USA)], or had arterial/alveolar oxygen tension ratio $\mathrm{PaO}_{2} / \mathrm{PAO}_{2}(\mathrm{a} / \mathrm{A})$ of $<0.22$ were intubated using an endotracheal tube (internal diameter, $3.0 \mathrm{~mm}$ ), ventilated using an SLE 2000 (SLE Co., Croydon, UK) according to the synchronized intermittent mandatory ventilation method and provided with surfactant replacement therapy (Survanta ${ }^{\circledR}$; Abbott Laboratories, Abbott Park, IL, USA). The total dose of surfactant was $100 \mathrm{mg}$ phospholipids $/ \mathrm{kg}$ birth weight $(4 \mathrm{ml} / \mathrm{kg})$, which was subsequently divided into four quarter-dose aliquots. Each of the four aliquots were administered in a different position, as follows: Head and body inclined $5-10^{\circ}$ with head turned to the right and left, respectively; and head and body declined $5-10^{\circ}$ with head turned to the right and left, respectively. Surfactant replacement therapy was administered intratracheally by instillation through a 5 French end-hole catheter (16). Surfactant replacement therapy was repeated after 6-24 $\mathrm{h}$ when improvement of clinical and laboratory RDS results were not observed ( $\geq 3$ doses). The patients were then subjected to NCPAP following the improvement of their respiratory condition. The aim of the therapy was to maintain an a/A ratio of $>0.22, \mathrm{SpO}_{2}$ of $88-93 \%$ and $\mathrm{PaO}_{2}$ of $50-80 \mathrm{mmHg}(17,18)$.

Carnitine analysis. Carnitine levels were measured in the plasma samples collected from all patients during the first $6 \mathrm{~h}$ following birth and on day 7 following birth. Standard carnitine kits (Z13010; Eureka Lab Division S.r.l., Chiaravalle, Italy) were used for the analysis of carnitine levels. The present method facilitated the analysis of the plasma levels of L-carnitine base (free) via a specific derivatization solution, separation by high pressure liquid chromatography (Agilent 1100; Agilent Technologies GmbH, Waldbronn, Germany) and subsequent quantification using fluorimetry.

Statistical analysis. The results are expressed as the mean \pm standard deviation. A Kolmogorov-Smirnov test was used to determine the normality of the data. Statistical differences between the groups were analyzed using Student's $\mathrm{t}$-test. Discrete variables were compared using a Pearson $\chi^{2}$ test. The Pearson correlation test was used to determine the correlations among the variables. Data analysis was performed using SPSS software, version 17.0 (SPSS, Inc., Chicago, IL, USA). 
Table I. Characteristics of infants with or without RDS.

\begin{tabular}{lccccc}
\hline & \multicolumn{2}{c}{ Experimental groups (1 and 2) } & & \multicolumn{2}{c}{ Control groups (3 and 4) } \\
\cline { 2 - 3 } Parameter & RDS (n=30) & Non-RDS (n=35) & & RDS (n=31) & Non-RDS (n=34) \\
\hline Day 1 carnitine $(\mu \mathrm{mol} / \mathrm{l})$ & $22.6 \pm 3.1$ & $25.5 \pm 3.2$ & & $22.0 \pm 3.7$ & $24.3 \pm 2.6$ \\
Gender (Male/female) & $17 / 13$ & $20 / 15$ & & $18 / 13$ & $19 / 15$ \\
Birth weight (g) & $1,650.2 \pm 328.3$ & $1,630.1 \pm 282.2$ & & $1,670.4 \pm 311.4$ & $1,610.2 \pm 283.6$ \\
Gestational age (weeks) & $33.3 \pm 1.8$ & $33.1 \pm 2.9$ & & $33.1 \pm 1.7$ & $32.8 \pm 2.6$ \\
Maternal age (years) & $26.8 \pm 3.5$ & $27.4 \pm 3.8$ & & $25.9 \pm 3.7$ & $28.1 \pm 2.6$ \\
Apgar score & $7(6-8)$ & & & $7(5-8)$ & $7(6-8)$ \\
1 min $^{\mathrm{a}}$ & $9(8-10)$ & $9(8-10)$ & & $9(8-10)$ & $9(7-10)$ \\
5 min $^{\mathrm{a}}$ & $21(70 \%)$ & $20(57 \%)$ & & $22(71 \%)$ & $15(54 \%)$ \\
Cesarean section & $2(1-4)$ & $3(2-5)$ & $2(1-3)$ & $3(2-4)$ \\
Parity (n) & & & & \\
\hline
\end{tabular}

${ }^{\mathrm{a}}$ Median (range). RDS, respiratory distress syndrome.

Table II. Carnitine levels of the experimental (1/2) and control (3/4) groups on days 1 and 7 following birth.

\begin{tabular}{lccc}
\hline & \multicolumn{2}{c}{ Carnitine level $(\mu \mathrm{mol} / \mathrm{l})$} & \\
\cline { 2 - 3 } Day & Experimental $(\mathrm{n}=65)$ & Control $(\mathrm{n}=65)$ & P-value \\
\hline 1 & $24.1 \pm 3.5$ & $23.1 \pm 3.4$ & $\mathrm{NS}$ \\
7 & $18.8 \pm 2.3$ & $11.9 \pm 2.2$ & 0.02
\end{tabular}

NS, not significant.

Table III. Carnitine levels in the RDS (1/3) and non-RDS (2/4) groups on days 1 and 7 following birth.

\begin{tabular}{lccc} 
& \multicolumn{2}{c}{ Carnitine level $(\mu \mathrm{mol} / \mathrm{l})$} & \\
\cline { 2 - 3 } Day & RDS $(\mathrm{n}=61)$ & Non-RDS $(\mathrm{n}=69)$ & P-value \\
\hline 1 & $21.3 \pm 3.4$ & $26.0 \pm 3.0$ & 0.01 \\
7 & $14.5 \pm 2.2$ & $17.2 \pm 2.0$ & 0.01 \\
\hline
\end{tabular}

RDS, respiratory distress syndrome.

\section{Results}

Patient characteristics. A total of 130 preterm infants, including 56 females and 74 males, were enrolled in the present study. The mean gestational age was $32.8 \pm 2.9$ weeks (range, 28-36 weeks). The average birth weight of the infants was $1,645.4 \pm 304.6 \mathrm{~g}$; the mean birth weight for the experimental group infants was $1,639.2 \pm 322.7 \mathrm{~g}$ and that of the control group infants was $1,631.3 \pm 299.8 \mathrm{~g}$. Baseline characteristics of the infants with and without RDS are presented in Table I.
Table IV. Correlation between carnitine levels, birth weight and Apgar score.

\begin{tabular}{lcc}
\hline Parameter & Correlation coefficient (r) & P-value \\
\hline Birth weight & -0.51 & 0.01 \\
Apgar score & 0.26 & 0.02 \\
\hline
\end{tabular}

Carnitine levels. Following comparison of serum carnitine levels, no significant difference was observed on day 1 of measurements; however, on day 7 the carnitine levels were significantly higher in the experimental groups, as compared with the control groups $(\mathrm{P}=0.02$; Table II).

When all patients were compared (experimental and control, RDS and non-RDS groups) for carnitine levels on days 1 and 7, it was observed that in the non-RDS group carnitine levels were significantly higher compared with the RDS group $(\mathrm{P}=0.01$; Table III).

On day 1 the serum carnitine levels of all patients were evaluated, and no correlation was observed between carnitine levels and gender. However, a negative correlation between carnitine levels and birth weight and a positive correlation between carnitine levels and Apgar scores was observed. Serum carnitine levels therefore increased as birth weight decreased, and increased in positive correlation with Apgar scores (Table IV).

Effects of carnitine therapy. The surfactant requirement values, which were the number of rounds of surfactant therapy required, were $1.56 \pm 0.97$ and $2.12 \pm 0.99$ in groups 1 and 3 , respectively (Table V). Statistical comparison indicated that group 1 (RDS treated with carnitine) required significantly less surfactant compared with group 3 .

The mean durations of mechanical ventilation support were $3.04 \pm 3.6$ and $4.73 \pm 5.63$ days in groups 1 and 3 , respectively. The mean duration of mechanical ventilation was therefore significantly reduced in group 1 , compared with group $3(\mathrm{P}<0.001$; 
Table V. Surfactant therapy, MV and BPD development in patients with RDS in the experimental and control groups.

\begin{tabular}{lccr}
\hline Parameter & Group 1 $(\mathrm{n}=30)$ & Group 3 $(\mathrm{n}=31)$ & P-value \\
\hline Surfactant $(\mathrm{n})$ & $1.56 \pm 0.97$ & $2.12 \pm 0.99$ & $<0.001$ \\
Patients requiring surfactant $(\mathrm{n})$ & $12(40 \%)$ & $17(55 \%)$ & $<0.001$ \\
MV duration (days) & $3.04 \pm 3.6$ & $4.73 \pm 5.6$ & $<0.001$ \\
Carnitine level $(\mu \mathrm{mol} / \mathrm{l})$ & & & $\mathrm{NS}$ \\
Day 1 & $22.6 \pm 3.1$ & $22.0 \pm 3.7$ & $<0.001$ \\
Day 7 & $16.3 \pm 2.7$ & $12.8 \pm 2.8$ & NS \\
Patients with BPD $(\mathrm{n})$ & 2 & 4 & \\
\hline
\end{tabular}

MV, mechanical ventilation; BPD, bronchopulmonary dysplasia; RDS, respiratory distress syndrome; NS, not significant.

Table V). A total of 12 patients (40\%) in group 1 required mechanic ventilation and surfactant (mechanical ventilation and surfactant therapy criteria are the same), while 17 patients $(55 \%)$ required mechanic ventilation and surfactant therapy in group 3 ( $\mathrm{P}<0.001$; Table V).

BPD was observed in 2 patients in group 1 and 4 patients in group 3 , although this was not statistically significant $(\mathrm{P}=0.07)$.

\section{Discussion}

Previous studies have demonstrated that carnitine is crucially involved in the development of RDS and the carnitine status of patients with RDS $(2,3,19)$. The results of the present study indicated that the duration of mechanical ventilation and the requirement for surfactant therapy was significantly reduced in the groups that received L-carnitine treatment, as compared with the control groups. A similar study was conducted by Crill et al (20), who reported that the requirement for mechanical ventilation, duration of ventilator use, and the incidence of BPD was not significantly different between the therapy and placebo groups. In the present study, BPD incidence was decreased in the groups treated with L-carnitine, although this difference was not statistically significant. Therefore, the results of the current study were not concordant with those reported by Crill et al (20). This may be due to the difference in carnitine dosage. Crill et al (20) used L-carnitine at a dosage of $20 \mathrm{mg} / \mathrm{kg} / \mathrm{day}$ for all infants; however, in the present study a dose of $30 \mathrm{mg} / \mathrm{kg} /$ day was used. In all patients with RDS, carnitine levels were higher on day 7 in the groups treated with carnitine, as compared with the control groups, although this difference was not statistically significant. In a previous study that did use carnitine treatment, the levels of carnitine were significantly higher in patients without RDS (2).

In the present study, infants with RDS that were treated with L-carnitine exhibited a decreased serum carnitine concentration compared with non-RDS patients on days 1 and 7. These results were concordant with those of previous studies that investigated serum L-carnitine levels in patients with or without RDS $(2,3)$. In the present study, serum carnitine levels on day 1 were not associated with the gender of the patients, but did show a negative correlation with birth weight and a positive correlation with Apgar scores. This may due to the increased requirement for surfactant synthesis in low birth weight infants as compared with infants with high Apgar scores that exhibit a healthy respiratory pattern. In two previous studies $(2,3)$, no significant differences were reported between L-carnitine levels and gender, birth weight and Apgar scores. Patients with RDS treated with L-carnitine did not exhibit higher serum carnitine levels on day 7 compared with the control group.

It has been previously proposed that L-carnitine administered to RDS patients may be used for surfactant synthesis $(5,6,19)$. Antenatally-administered carnitine has been demonstrated to accelerate the maturation of fetal lungs in rabbits (5). Furthermore, treatment of pregnant rats with carnitine resulted in a significant increase in total phospholipids and dipalmitoylphosphatidylcholine levels in fetal rat lungs $(19,21)$. Palmitoylcarnitine is a form of carnitine that has been reported to have properties as a surface active molecule or surfactant, and functions as an intermediate in mitochondrial fatty acid oxidation (22). Palmitoylcarnitine may decrease the surface tension of the alveoli, and deficiency in palmitoylcarnitine may lead to the development of RDS.

In the present study, patients with RDS treated with carnitine had better results compared with the untreated group, including: Reduced surfactant requirement values; decreased number of patients requiring surfactant; shorter durations of mechanic ventilation; and fewer incidences of BPD. The data demonstrated the efficacy of treatment with L-carnitine and the consequences of carnitine deficiency. The transport of L-carnitine to the lungs of the premature infant likely increases for surfactant synthesis, and this may cause the reduced serum levels of carnitine observed in patients with RDS. Following birth there is a marked increase in energy metabolism. Premature infants with RDS require more energy due to their increased respiratory effort $(23,24)$. It is well-established that carnitine serves a crucial function in cellular metabolic processes, such as aerobic catabolism of glucose and $\beta$ oxidation of free fatty acids $(23,24)$. Due to its role in metabolism, the diaphragmatic muscle requires carnitine for contractility (25). Premature infants may have lower glycogen levels, and therefore use more carnitine for fatty acid oxidation, leading to a decrease in carnitine levels.

In the present study, infants with a gestational age of 8-32 weeks had higher serum L-carnitine levels on the first day following birth compared with those with a gestational age of 32-36 weeks. Previous studies conducted by Meyburg et al (26) and Giannacopolou et al (27) reported a negative correlation 
between gestational age and serum carnitine concentrations Conversely, Ozturk et al (2) did not establish a correlation between carnitine and gestational age.

The present study included a number of limitations. The carnitine levels of the mothers were not evaluated during the gestational period, and maternal carnitine levels may have affected carnitine levels in the infants. In addition, carnitine levels in the lung tissue of the infants were not examined.

The treatment dose of carnitine was $30 \mathrm{mg} / \mathrm{kg}$ in the current study; however, higher doses should be used in future studies.

Surfactant replacement requirement in RDS patients was significantly different in the group treated with carnitine, as compared with the control group. Therefore, the group treated with L-carnitine required less surfactant, which may decrease the number of complications and provide more cost-effective therapy. A total of 12 patients (40\%) in group 1 required mechanic ventilation and surfactant replacement therapy, while a significantly greater number of patients (17 patients; $55 \%$ ) required mechanic ventilation and surfactant therapy in group 3. Zaharia et al (28) reported that $54 \%$ of preterm infants $>28$ weeks of gestational age that received prophylactic NCPAP required mechanical ventilation.

In conclusion, the results of the present study suggested that early carnitine therapy should be administered to infants with RDS, as it is known to increase the synthesis of surfactant. Treating premature infants with RDS with carnitine may allow decreased duration of mechanical ventilation, the use of less surfactant, and decreased occurrence of BPD. L-carnitine levels are important in patients with RDS as they have decreased levels of surfactant, low production of energy, and weakness of diaphragm muscle contractibility $(2,23)$. Further studies are required in larger populations to further examine the therapeutic and antenatal prophylactic use of L-carnitine in preterm infants with RDS.

\section{Acknowledgements}

The present study was supported by the Scientific Research Center of Erciyes University (grant no. TSU-11-3539)

\section{References}

1. Hislop AA: Fetal and postnatal anatomical lung development. In: Neonatal Respiratory Disorders. Greenough A and Milner AD (eds). 2nd edition. Arnold Press, London, pp247-251, 2003.

2. Ozturk MA, Gunes T, Koklu E and Erciyes A: Free carnitine levels in respiratory distress syndrome during the first week of life. Am J Perinatol 23: 445-459, 2006

3. Korkmaz A, Tekinalp G, Coskun T, Yigit S and Yurdakok M: Plasma carnitine levels in preterm infants with respiratory distress syndrome. Pediatr Int 47: 49-52, 2005.

4. Harmeyer J: The physiological role of L-carnitine. Lohninger Information 27: 1-8, 2002

5. Czeszyńska MB: Evaluation of fetal lung maturation in rabbits after giving carnitine and carnitine with betamethasone to pregnant rabbits. Ann Acad Med Stetin 39: 185-205, 1993 (In Polish).

6. Salzer H, Husslein P, Lohninger A, Binstorfer E, Langer M, Schönbauer M, Wagner G, Simbruner G and Popow C: 1st report: Alternatives to cortisone therapy, 1st clinical experiences with a carnitine-betamethasone combination for the stimulation of the fetal lung maturity. Wien Klin Wochenschr 95: 724-728, 1983 (In German).

7. Whitfield J, Smith T, Sollohub H, Sweetman L and Roe CR: Clinical effects of L-carnitine supplementation on apnea and growth in very low birth weight infants. Pediatrics 111: 477-482, 2003.
8. Kumar M, Kabra N and Paes B: Role of carnitine supplementation in apnea of prematurity: A systematic review. J Perinatol 24: 158-163, 2004

9. Kurz C, Arbeiter K, Obermair A, Salzer H, Salzer HR and Lohninger A: L-carnitine-betamethasone combination therapy versus betamethasone therapy alone in prevention of respiratory distress syndrome. Z Geburtshilfe Perinatol 197: 215-219, 1993. (In German)

10. Ballard JL, Khoury JC, Wedig K, Wang L, Eilers-Walsman BL and Lipp R: New Ballard Score, expanded to include extremely premature infants. J Pediatr 119: 417-23, 1991.

11. Jackson JC: Respiratory distress in the preterm infant. In: Avery's Diseases of the Newborn. Gleason CA and Devaskar US (eds). 9th edition. Elsevier Saunders, Philadelphia, PA, pp633-646, 2012.

12. Jobe AH and Bancalar E: Hormoncuklardan dysplasia. Am J Respir Crit Care Med 163: 1723-1729, 2001.

13. Carlo WA: The newborn infant. In: Nelson Textbook of Pediatrics. Kliegman RM, Stanton BF, St. Geme JF III, Schor NF and Behrman RE (eds). 19th edition. Elsevier Saunders Press, Philadelphia, PA, pp561-569, 2011.

14. Schulz KF, Altman DG and Moher D; CONSORT Group: CONSORT 2010 Statement: Updated guidelines for reporting parallel group randomised trials. BMC Med 8: 18, 2010.

15. Bancalari E, Claure N: Principles of respiratory monitoring and therapy. In: Avery's diseases of the newborn. Gleason CA and Devaskar SU (eds). 9th edition. Elseiver Saunders Press, Philadelphia, PA, pp.612-632, 2012

16. Douma C, Dawodu T, Patnode R: Appendix A: Common NICU medication guidelines. In: Manuel of Neonatal Care. Cloherty JH, Eichenwald EC and Stark AR (eds). 6th edition. Lippincott Williams \& Wilkins, Philadelphia, PA, pp675-715, 2008.

17. Eichenwald EC: Mechanical ventilation. In: Manuel of Neonatal Care. Cloherty JP, Eichenwald EC and Stark AR (eds). 6th edition. Lippincott Williams \& Wilkins, Philadelphia, PA, pp331-343, 2008.

18. British Columbia Reproductive Care Program: Newborn Guideline 6: Surfactant replacement therapy in neonates. British Columbia Reproductive Care Program, British Columbia, Canada, 2003.

19. Lohninger A, Krieglsteiner HP, Hajos F, Stangl H and Marz R: Effects of prenatal treatment with betamethasone, L-carnitine, or betamethasone-L-carnitine combinations on the phosphatidylcholine content and composition of the foetal and maternal rat lung. Eur J Clin Chem Clin Biochem 34: 387-391, 1996.

20. Crill CM, Storm MC, Christensen ML, Hankins CT, Bruce Jenkins M and Helms RA: Carnitine supplementation in premature neonates: Effect on plasma and red blood cell total carnitine concentrations, nutrition parameters and morbidity. Clin Nutr 25: 886-896, 2006

21. Lohninger A, Krieglsteiner HP, Salzer H, Erhardt W, Eppl W and Kaiser E: Studies on the effects of L-thyroxine, L-carnitine and an L-thyroxine-L-carnitine combination on dipalmitoyl phosphatidylcholine content and on phosphatidylcholine species composition in fetal rat lungs. Pediatr Res 20: 1280-1283, 1986.

22. Goñi FM, Requero MA and Alonso A: Palmitoylcarnitine, a surface-active metabolite. FEBS Lett 390: 1-5, 1996.

23. Arenas J, Huertas R, Campos Y, Díaz AE Villalón JM and Vilas E: Effects of L-carnitine on the pyruvate dehydrogenase complex and carnitine palmitoyl transferase activities in muscle of endurance athletes. FEBS Lett 341: 91-93, 1994.

24. Novak M: Carnitine in perinatal metabolism of lipids. In: L-Carnitine and its Role in Medicine: From Function to Therapy. Ferrari R, Di Mauro S and Sherwood G (eds). 2nd edition. Academic Press, London and New York, pp104-112, 1992.

25. Hiatt WR, Regensteiner JG, Wolfel EE, Ruff L and Brass EP: Carnitine and acylcarnitine metabolism during exercise in humans. Dependence on skeletal muscle metabolic state. J Clin Invest 84: $1167-1173,1989$.

26. Meyburg J, Schulze A, Kohlmueller D, Pöschl J, Linderkamp O, Hoffmann GF and Mayatepek E: Acylcarnitine profiles of preterm infants over the first four weeks of life. Pediatric Res 52: 720-723, 2002.

27. Giannocopoulou C, Evangeliou A, Matalliotakis I, Relakis K, Sbirakis N, Hatzidaki E and Koumandakis E: Effect of gestation age and birth weight in the concentration of carnitine in the umbilical plasma. Clin Exp Obstet Gynecol 25: 42-45, 1998.

28. Zaharia G, Ion DA, Schmidt N, Popa M, Kudor-Szabadi I and Zaharia T: Prophylactic versus therapeutic CPAP in preterm newborns of 28-32 gestational weeks. Pneumonologia 57: 34-37, 2008 (In Romanian). 